QS А. Грённ и О. Клонова (ред.) Русский язык в контрастивном аспекте, Oslo Studies in Language 2(3), 2010. 641-650. (ISSN 1890-9639)

http://www.journals.uio.no/osla

\title{
НАБОКОВСКАЯ КОНЦЕПЦИЯ ЛИЧНОЙ ОРГАНИЗАЦИИ ВРЕМЕНИ: КОНТРАСТИВНЫЕ АСПЕКТЫ АВТОРИЗОВАННОГО ПЕРЕВОДА РОМАНА «ЛОЛИТА»
}

\author{
Игорь Кудряшов \\ Южньй федеральньй университет
}

АннотАция

Синонимические соответствия временных пропозиций в английском варианте и авторизованном переводе романа «Лолита» - это не всегда пословные, а более сложные отношения, поэтому их исследование характеризуется установлением отношений между одной пропозицией исходного языка и несколькими языковыми единицами синонимического ряда в языке перевода.

\section{[1] ВвЕДЕНИЕ}

Авторский выбор межъязыковых синонимичных темпоральных пропозиций связан с проблемой билингвизма в индивидуально-личностном аспекте. За синонимичным соотношением межъязыковых темпоральных пропозиций скрываются усилия языковой личности автора в поисках новых средств познания философской категории времени, выражения мыслей и чувств.

Синонимичными темпоральными пропозициями - в том числе и на межъязыковом уровне - мы считаем такие синтаксические конструкции, в которых содержатся сходные синтаксические отношения, тождественное значение, создаваемое семантически близкими словами, выполняющими одинаковую стилистическую функцию, но структурно различно организованных. Отношения между оригиналом и текстом перевода при соблюдении синонимичности темпоральных пропозиций характеризуются, на наш взгляд, следующими общими особенностями, характерных для эквивалентности синтаксических структур:

- значительный, хотя и неполный параллелизм лексического состава для большинства слов оригинала можно отыскать соответствующие слова в переводе с близким содержанием; 
- использование в переводе синтаксических структур, аналогичных структурам оригинала или связанных с ними отношениями синтаксического варьирования, что обеспечивает максимально возможную передачу в переводе значения синтаксических структур оригинала;

- сохранение в переводе всех трех частей содержания оригинала, характеризующих предыдущий тип эквивалентности: цели коммуникации, указания на ситуацию и способа ее описания (Паршин 2000, 136-137).

При невозможности полностью сохранить синтаксический параллелизм несколько меньшая степень инвариантности синтаксических значений достигается путем использования в переводе структур, связанных с аналогичной структурой отношениями синтаксического варьирования. При этом отмечаются три основных вида такого варьирования:

- использование синонимичных структур, связанных отношениями прямой или обратной трансформации;

• использование аналогичных структур с изменением порядка слов;

- использование аналогичных структур с изменением типа связи между ними (Паршин 2000, 138-139).

Синонимичные темпоральные пропозиции в тексте ориганала и тексте перевода предстают маркерами определенных нюансов движения и направления авторской мысли, а также многообразия смысловых отношений, которые не всегда находятся на поверхности. Данные смысловые отношения актуализируются в авторском мышлении (при порождении текста) и читательском восприятии текста и вытекают из столкновения или наложения значений синонимов при функционировании в художественной речи.

Согласно нашим наблюдениям, В. Набоков в авторизованном переводе романа «Лолита» при оформлении темпоральных пропозиций учитывает наличие фонового, прагматического уровня информации обоих языков, умело эксплуатирует особенности английской и русской картин мира. При этом следует иметь в виду, что синтаксическая структура предложений в англоязычных романах В. Набокова очень близка к синтаксической структуре их соответствующих русских автопереводов, что служит отражением индивидуального писательского билингвизма: присутствия лингвистической доминанты русского языка по отношению к английскому языку.

Анализ интегративного взаимодействия синонимичных временных пропозиций, обладающих межъязыковым характером, проводится нами в два этапа. Сначала анализируются языковые формы и определяется то общее, 
что есть между ними согласно методике описания значения языковых выражений, предложенной в ряде семантических работ логико-философского и лингвистического направлений: смыслом языкового выражения является класс всех языковых выражений, синонимичных с данным (Жилин 1974; Кононенко 1970; Кравец 2001). Затем нами устанавливаются смысловые различия между межъязыковыми синонимами. Различия соотносятся с реализацией авторских личностных смыслов в тексте оригинала и тексте перевода, совокупность которых образует семантику личностной пристрастности писателя. Предложенный анализ позволил нам перейти к исследованию синонимического соотношения темпоральных пропозиций в конкретном предложении и/или тексте.

Для обеспечения смысловой целостности текста оригинала и текста перевода для языковой личности писателя оказывается важным не только правильно выбрать ту или иную языковую единицу из межъязыкового синонимического ряда, но и определить, какой из синонимов может открывать или какой из них может закрывать синонимическое соотношение. В ходе анализа текста оригинала и текста авторизованного перевода романа «Лолита» установлено, что последовательность расположения межъязыковых синонимичных временных пропозиций соответствует определенным закономерностям, обусловленным не только английской и русской картинами мира, но и единой и неизменной системой авторского мышления, понимаемого нами как своеобразный динамический процесс.

Специфическая цель конкретного акта перевода заключается в стремлении оказать на англо- и на русскоязычного читателя воздействие, непосредственно связанное с содержанием, прагматическим потенциалом оригинала и подлинника. Поскольку перевод предназначен для иного реципиента, нежели оригинал, возникает необходимость прагматической адаптации перевода, т.е. внесения определённых поправок на социально-культурные, психологические и иные различия между реципиентами оригинального и переводного текстов в соответствии с их языковыми картинами мира. При этом адекватность перевода напрямую зависит от сохранения прагматики оригинала.

В оригинале и авторизованном переводе романа «Лолита» между семиотически значимыми темпоральными планами повествования, создаваемыми пропозициями, образуется как унисонное единство, так и значимый семантический «зазор». Единство и несовпадение планов художественного времени в оригинале и переводе романа определяется как картиной мира самого писателя, так и семиотическими системами времени английского и русского языков, которыми руководствовался В. Набоков при написании (на английском языке) и переводе (на русский язык) романа «Лолита». 
Жизненная активность Гумберта также отражает определенную организацию времени его бытия, наблюдение за предметами в текущее время восприятия. В дискурсе В. В. Набокова временная пропозиция оказывается значимым элементом в отражении разных качеств бытия Гумберта в мире. За синонимическим соотношением временных пропозиций скрываются усилия творческого сознания автора в поисках новых средств познания временных модусов Я-концепции, проблемы психологического времени Гумберта во взаимосвязи с социальным временем. Синонимия временных пропозиций обнаруживается как общность функциональных характеристик компонентов предложения, а ее пределы определяются наличием формализованных показателей.

Целесообразно, на наш взгляд, соотнести характеристики личностной организации времени героя и его способность к организации времени жизни, жизненного пути, т.е. последовательность жизненного процесса, имеющего свою временную архитектонику, темпоральную структуру в подлиннике романа и его переводе на русский язык.

[2] КОГНИТИВНАЯ ПРИРОДА НЕЭКВИВАЛЕНТНОСТИ ТЕМПОРАЛЬНЫХ ПРОПОЗИЦИЙ В ОРИГИНАЛЕ И АВТОРСКОМ ПЕРЕВОДЕ РОМАНА «ЛОЛИТА»

Жизненная активность героя есть способ разрешения противоречия, возникающего во взаимодействии его личности с жизнью, ее обстоятельствами, условиями. Жизненная активность героя в таком понимании выступает как самоорганизация его личности во времени, отражаемого в тексте романа темпоральными пропозициями.

Набоковская концепция личностной организации времени постулирует активность личности в восприятии, переживании, осознании и организации времени своей жизни, тем самым в ней выделяется самый высший темпоральный пласт - личностное время. В процессе такой личностной активности персонаж организует время своей жизни, влияет на него. Такая организация подразумевает воздействие персонажа на переживание хода времени, на осознание прошлого своего жизненного пути, на осуществление деятельностной активности по преобразованию условий окружающего мира. Субъективное воздействие персонажа на время, отражаемое темпоральными пропозициями, представлено в подлиннике и переводе романа, согласно нашим наблюдениям, неэквивалентными языковыми средствами. Их неэквивалентность - результат адаптации субъективного времени персонажа к английской и русской языковым картинам мира. Подобная адаптация предполагает референтное переключение в тексте перевода (т.е. в тексте оригинала и тексте перевода наблюдается разная интенсивность проявления темпорального смысла), что, в свою очередь, маркируется сменой модусных регистров. 
Субъективность - качество не универсальное, а оригинальное в рамках определенной картины мира (Бабушкин 2001; Корнилов 2003). Данное положение и определяет неэквивалентность темпоральных пропозиций, отражающих жизненную активность Гумберта, в оригинале и авторском переводе романа «Лолита».

[3] МЕЖЪЯЗЫКОВАЯ НЕЭКВИВАЛЕНТНОСТЬ ВРЕМЕННЫХ ПРОПОЗИЦИЙ ПРИ ОТРАЖЕНИИ УСКОРЕНИЯ СУБЪЕКТИВНОГО ВРЕМЕНИ ГУМБЕРТА

Для Гумберта характерно то ускорение, то замедление субъективного времени. Ускорение субъективного времени он ощущает как растяжение временного промежутка событий, замедление скорости внешних процессов.

(1) "Another time a red-haired school girl hung over me in the metro, and a revelation of axillary russet I obtained remained in my blood for weeks..." «Другой раз рыжеволосая школьница повисла надо мною в вагоне метро, и оранжевый пушок у нее под мышкой был откровением, оставшимся на много недель у меня в крови...»

(2) "...the couple had somehow got over to California and had been used there, for an excellent salary, in a year-long experiment conducted by a distinguished American ethnologist..."

«Она с мужем каким-то образом попала из Франции в Калифорнию; там, в продолжение целого года, за отличный оклад, они служили объектами опыта, производившегося известным американским этнологом...»

Как показывают примеры, в русскоязычном переводе романа «Лолита» темпоральные пропозиции передают большую растяженность временного промежутка событий, субъективное время Гумберта оказывается более «растянутым» в объективном времени, чем в оригинале романа. В переводе романа на русский язык Гумберт предстает более пассивным на протяжении всего переживания событий, чем в оригинале романа.

Другими словами, временная пропозиция для В. Набокова-средство адаптации характера героя к языковым картинам мира англо- и русскоязычных читателей. В русской версии романа состояние Гумберта сопровождается субъективным ощущением растянутости темпорального промежутка, и за счет этого заполняется когнитивными событиями внутреннего плана (мыслями, образами). Ускорение субъективного времени сопровождается ощущением, что объективное время тянется очень долго по отношению к какомунибудь внешнему событию. Как представляется, подобная набоковская концепция субъективного времени отражает в переводе романа русскую языко- 
вую картину мира, что потребовало определенного уточнения темпоральных пропозиций в переводе романа по сравнению с оригиналом.

[4] МЕЖЪЯЗЫКОВАЯ НЕЭКВИВАЛЕНТНОСТЬ ВРЕМЕННЫХ ПРОПОЗИЦИЙ ПРИ ОТРАЖЕНИИ ЗАМЕДЛЕНИЯ СУБЪЕКТИВНОГО ВРЕМЕНИ ГУМБЕРТА

При замедлении субъективного времени Гумберт, наоборот, ощущает снижение скорости внутренних процессов, сжатие временных промежутков. Как в тексте оригинала, так и в тексте перевода герой осознает, что за субъективно краткий временной интервал в окружающей реальности произошло слишком много событий.

(3) "The first volume took me a couple of years during which I put in seldom less than fifteen hours of work daily..."

«Первый том занял у меня два года работы, причем я редкий день трудился меньше пятнадцати часов...»

(4) "In the course of the sun-shot moment that my glance slithered over the kneeling child (her eyes blinking over those stern dark spectacles - the little Herr Doktor who was to cure me of all my aches) while I passed by her in my adult disguise (a great big handsome hunk of movieland manhood), the vacuum of my soul managed to suck in every detail of her bright beauty, and these I checked against the features of my dead bride..."

«B тот солнцем пронизанный миг, за который мой взгляд успел оползти коленопреклонную девочку (моргавшую поверх строгих темных очков - о, маленький Herr Doktor, которому было суждено вылечить меня ото всех болей), пока я шел мимо нее под личиной зрелости (в образе статного мужественного красавца, героя экрана), пустота моей души успела вобрать все подробности ее яркой прелести и сравнить их с чертами моей умершей невесты...»

В оригинале романа сжатие временных промежутков передается темпоральными пропозициями, подчеркивающими неопределенность сжатого момента времени, причем данный момент дан как бы в процессе, незавершении, что передает субъективное переживание длительности данного момента (ср., как в (4) In the course of the sun-shot moment-B тот солнцем пронизанный миг). В русском переводе временные пропозиции указывают на определенность сжатого момента в прошлом, они не указывают на субъективное переживание длительности. О замедлении своего времени герой судит не по длительности момента (как в оригинале), а по количеству событий, произошедших извне. 
[5] КОНТРАСТИВНОСТЬ ВРЕМЕННЫХ ПРОПОЗИЦИЙ В ОРИГИНАЛЕ И ПЕРЕВОДЕ РОМАНА «ЛОЛИТА» КАК ИНДИКАТОРЫ ПЛОТНОСТИ ПЕРЕЖИВАНИЯ ВРЕМЕНИ ГУМБЕРТОМ

Согласно нашим наблюдениям, ускорение субъективного времени достаточно характерно для Гумберта и разнообразно в своих проявлениях. Для номинации данного явления мы взяли название, введенное астрономом Н. А. Козыревым для обозначения активного свойства времени. Согласно его теории, «у времени, кроме направленности хода, есть еще одно физическое свойство - его плотность» (Козырев 1991). Это свойство, по его мнению, кроме причинно-следственного аспекта, может быть косвенно связано с насыщенностью психологического времени: «возможно, что наше психологическое ощущение пустого или содержательного времени имеет не только субъективную природу, но, подобно ощущению времени, имеет и объективную физическую природу» (Козырев 1991).

Под плотностью переживания времени литературным героем будем понимать глубину переживания, уровень задействованности в нем таких психологических систем, как мышление, воображение. Личностная организация времени Гумбертом включает в себя такую составляющую, как переживание времени. Временные пропозиции в оригинале и авторском переводе романа подчеркивают разную плотность переживания времени.

В языке оригинала временные пропозиции, как мы заметили, передают малую плотность подобного переживания времени. Временные пропозиции оригинала романа подчеркивают переживание времени Гумбертом, которое включает в себя только субъективное ощущение, что время замедлилось. В оригинале произведения для Гумберта характерно ощущение того, что собственное время растянулось, а внешнее тянется еле-еле, замедлилось. Обычно это обнаруживается в ситуациях ожидания, скуки, неприятия.

(5) "There were other unpleasant incidents. There was the movie theatre once, for example. Lo at the time still had for the cinema a veritable passion (it was to decline into tepid condescension during her second high school year). We took in, voluptuously and indiscriminately, oh, I don't know, one hundred and fifty or two hundred programs during that one year, and during some of the denser periods of movie-going we saw many of the newsreels up to half-a-dozen times since the same weekly one went with different main pictures and pursued us from town to town..."

«Случались и другие неприятности. Раз в кино, например. $B$ то время Лолита еще питала к нему истинную страсть (которая сократилась потом до вялой снисходительности, когда она опять стала ходить в гимназию). Мы просмотрели за один год, с неразборчивым упоением, около ста пятидесяти или даже двухсот программ, причем иногда нам прихо- 
дилось видеть ту же хронику по несколько раз, оттого что различные главные картины сопровождались одним и тем же выпуском киножурнала, тянувшимся за нами из городка в городок...»

Тот факт, что в субъективных ощущениях Гумберта внешнее время замедлилось, «растянулось», в оригинале романа подчеркивается временными пропозициями процессуальной семантики (ср., в (5) during her second high school year, during that one year, during some of the denser periods of moviegoing). Однако данные темпоральные пропозиции в воспоминаниях героя сопровождают одновременно множество действий в Past Simple, имеющем значение повторяющихся действий в прошлом. За счет этого в тексте подлинника романа создается прагматический эффект растянутости собственного, внутреннего времени Гумберта. Другими словами, в оригинале произведения субъективно растянувшийся промежуток внутреннего времени заполняется в сознании Гумберта перцептивными картинами, мыслями, образами (картинами своей жизни).

В русском переводе романа временные пропозиции, напротив, обладают непроцессуальной семантикой (ср., в (5) когда она опять стала ходить в гимназию, за один год). Пример (5) также выявляет тот факт, что один из маркеров временной пропозиции подлинника, обладающий процессуальной семантикой (during that one year, during some of the denser periods of movie-going), в русском переводе вообще отсутствует, его темпоральное значение включается в семантику глагольной формы (мы) просмотрели.

В результате темпоральные пропозиции перевода романа, в отличие от его оригинала, передают высокую плотность переживания времени героем. В примере (5) переживание растянутости внутреннего времени при характеристике Гумберта сопровождается не обилием мыслей и чувств (как в оригинале), а выраженной двигательной активностью героя (упор в русском переводе делается при этом на глаголы совершенного вида-cmpacms сократилась, [Лолита] стала ходить в гимназию, мы просмотрели).

В связи с этим временные пропозиции в тексте перевода романа производят иной прагматический эффект: у русского читателя создается впечатление, что Гумберт перескакивает из объективной реальности в реальность другого уровня, необыденную реальность, в которой действуют другие законы природы, точнее, выпадает на некоторое время из константной реальности в реальность виртуальную. В русском переводе Гумберт переживает ускорение внутреннего времени, которое сопровождается ощущением замедленности времени внешнего (ср., с оригиналом романа, в котором подчеркивается факт растянутости внутреннего времени Гумберта). 


\section{[6] ЗАКЛюЧЕНИЕ}

В оригинале романа В. Набоков характеризует Гумберта как персонажа, внутреннее время которого растянуто. В переводе внутреннее время героя ускорено. Внешнее же время для героя тянется еле-еле, замедленно и в оригинале, и в переводе «Лолиты».

Очевидно, что в творческом сознании писателя русской языковой картине мира присущ больший динамизм внутреннего времени, чем в английской картине мира. Подобный вывод совпадает с заключением современных психологов по этому поводу (Абульханова \& Березина 2001), которые считают, что русские, периодически ускоряющие свое внутреннее время относительно внешнего (под действием стрессов, из-за собственной тревожности или неуемных амбиций), активнее других народов расходуют выделенное им количество жизненной энергии; англичане же наоборот ведут неторопливый, размеренный образ жизни, расходуют эту энергию крайне бережно, они могут замедлять свое внутреннее время.

Сравнительный анализ темпоральных пропозиций в оригинале и авторском переводе романа «Лолита» позволил нам выявить набоковскую концепцию времени, предполагающую разную соотнесенность объективного и субъективного времени в русской и английской языковых картинах мира. Основанием наших исследований, дававших возможность сравнения темпоральных пропозиций, явилась модель личностной организации времени персонажем, включавшая его осознание, переживание. Анализ темпоральных пропозиций позволил нам выявить неэквивалентную ориентацию Гумберта на внешнее (объективное) и внутреннее (субъективное) время в оригинале и переводе романа. Если в оригинале герой субъективно переживает замедление времени, то в авторском переводе-ускорение времени (поскольку герой в русском переводе ориентирован автором на внутреннее время, именно внутреннее время ускоряется).

Для Г. Гумберта как персонажа романа «Лолита» характерно «овладение» прошедшим временем. Это выражается в:

- творческой интенсивности когнитивного процесса реконструкции прошлой жизни;

- разрешении противоречий между объективными условиями и требованиями жизни и субъективными возможностями и потребностями, между разными объективными условиями и требованиями жизни, в которые вовлекался в прошлой жизни персонаж и которые порождали необходимость принятия им решений;

- разрешении противоречий, созданных самой активностью персонажа, его стремлении направить жизнь и ее обстоятельства в желаемое русло. 
Для решения подобного рода противоречий для автора необходима была субъективная рефлексия жизни персонажа, высокий уровень жизненных обобщений, которые осуществляются В. Набоковым в контексте главного темпорального вектора - смысла жизни Г. Гумберта, по-разному отраженного в подлиннике и переводе романа в связи с особенностями английской и русской картин мира.

\title{
СПИСОК ЛИТЕРАТУРЫ
}

Абульханова, К. А. \& Т. Н. Березина. 2001. Время личности и время жизни. СПб.: Алетейя.

Бабушкин, А. П. 2001. «Возможные миры» в семантическом пространстве языка. Воронеж: Издательство ВГУ.

Жилин, И. М. 1974. Синонимика в синтаксисе современного немецкого языка. Краснодар: КГУ.

Козырев, Н. А. 1991. Избранные труды. Л.: Наука.

Кононенко, В. И. 1970. Синонимика синтаксических конструкиий в современном русском языке. Киев: КГУ.

Корнилов, О. А. 2003. Языковые картины мира как производные национальных менталитетов. М.: ЧеРо.

Кравец, А. С. 2001. Типологическая структура смысла. Воронеж: ВГУ.

Паршин, А. 2000. Теория и практика перевода. М.: Русский язык.

\author{
АДРЕС АВТОРА \\ Игорь Кудряшов \\ Педагогический институт \\ Южного федерального университета \\ Кафедра русского языка и теории языка \\ Ул. Большая Садовая, 33 \\ Ростов-на-Дону \\ Россия \\ igalk@mail.ru
}

